\title{
Uncontrolled diabetes increases the risk of Alzheimer's disease: a population-based cohort study
}

\author{
W. L. Xu • E. von Strauss • C. X. Qiu • B. Winblad • \\ L. Fratiglioni
}

Received: 18 November 2008 / Accepted: 16 February 2009 / Published online: 12 March 2009

(C) Springer-Verlag 2009

\begin{abstract}
Aims/hypothesis Diabetes has been related to Alzheimer's disease with inconsistent findings. We aimed to clarify the association of diabetes with different dementing disorders taking into account glycaemic control, and to explore the link between glucose dysregulation and neurodegeneration. Methods A dementia-free cohort $(n=1,248)$ aged $\geq 75$ years was longitudinally examined to detect dementia, Alzheimer's disease and vascular dementia (VaD) cases (Diagnostic and Statistical Manual of Mental Disorders, revised third edition [DSM-III-R] criteria). The Alzheimer's disease diagnoses were subdivided into Alzheimer's disease with stroke and Alzheimer's disease without hypertension, heart disease and stroke. Diabetes was ascertained based on medical history, or hypoglycaemic medication use, or a random blood glucose level $\geq 11.0 \mathrm{mmol} / \mathrm{l}$, which included undiagnosed diabetes when neither a history of diabetes nor hypoglycaemic drugs use was present. Uncontrolled diabetes was classified as a random blood glucose level $\geq 11.0 \mathrm{mmol} / 1$ in diabetic patients. Borderline diabetes was defined as a random blood glucose level of 7.8-11.0 mmol/1 in diabetes-free individuals. Cox models were used to estimate HRs.

Results During the 9 year follow-up, 420 individuals developed dementia, including 47 with $\mathrm{VaD}$ and 320 with Alzheimer's disease (of the 320 Alzheimer's disease cases, 78 had previous, temporally unrelated stroke, and 137 had no major vascular comorbidities). Overall diabetes was only
\end{abstract}

W. L. Xu $(\bowtie) \cdot$ E. von Strauss · C. X. Qiu • B. Winblad •

L. Fratiglioni

Aging Research Center, Department of Neurobiology,

Care Sciences and Society,

Stockholm Gerontology Research Center, Karolinska Institutet,

Gävlegatan 16,

S-113 30 Stockholm, Sweden

e-mail: weili.xu@ki.se related to $\mathrm{VaD}$ (HR 3.21, 95\% CI 1.20-8.63). Undiagnosed diabetes led to an HR of 3.29 (95\% CI 1.20-9.01) for Alzheimer's disease. Diabetic patients with random blood glucose levels $<7.8 \mathrm{mmol} / 1$ showed no increased dementia risk. Uncontrolled and borderline diabetes were further associated with Alzheimer's disease without vascular comorbidities.

Conclusions/interpretation Uncontrolled diabetes increases the risk of Alzheimer's disease and VaD. Our findings suggest a direct link between glucose dysregulation and neurodegeneration.

Keywords Alzheimer's disease - Dementia - Diabetes · Glycaemic control · Vascular comorbidities ·

Vascular dementia

$\begin{array}{ll}\text { Abbreviations } \\ \text { DSM-III-R } & \begin{array}{l}\text { Diagnostic and Statistical Manual } \\ \text { of Mental Disorders, revised third edition }\end{array} \\ \text { IDE } & \text { Insulin-degrading enzyme } \\ \text { MMSE } & \text { Mini-Mental State Examination } \\ \text { VaD } & \text { Vascular dementia }\end{array}$

\section{Introduction}

Type 2 diabetes currently affects 250 million people worldwide [1], and about 300 million people with borderline diabetes are at increased risk of type 2 diabetes [2]. The global prevalent dementia cases are approximately 29 million, with 4.6 million new cases every year [3]. Population-based longitudinal studies have consistently reported that diabetes is associated with an increased risk of dementia, although the relationship between diabetes and Alzheimer-type dementia is less clear [4-16]. Some of these studies found that the association is due to an 
increased incidence of vascular dementia (VaD) $[6,8,16]$ or of Alzheimer's disease [4, 14], and only one study reported an increased incidence of both $\mathrm{VaD}$ and Alzheimer's disease [7]. Neuroimaging data have suggested that the increased risk of cognitive decline and dementia in patients with diabetes may be due to dual pathological processes involving both cerebrovascular damages and neurodegenerative changes [17].

There is convincing evidence that effective glycaemic control lowers the risk of several diabetes-related complications including stroke and neuropathy. A few studies have reported that diabetes-related cognitive deterioration may be attenuated by effective glycaemic control [18, 19], but none studied how the relationship between diabetes and dementia may be modulated by blood glucose levels. Diabetes is a known risk factor for vascular disorders, which, in turn, increase the risk of dementia [20]. Some studies suggested the mediating role of vascular diseases in the association of diabetes with impaired cognition or dementia [21, 22], and other reports showed a synergistic effect of diabetes and vascular disease on dementia risk [23-25]. Alternatively, there are mechanisms that may link diabetes with dementia. However, studies that addressed the relationship of diabetes with dementia focused on statistical independence of vascular comorbidities, rather than the causality of the association, which, from the point of view of mechanism, is more relevant. We have previously reported the association of diabetes with an increased risk of $\mathrm{VaD}$ [15]. In the present study, we sought to clarify the relationship of diabetes with different dementing disorders taking into account glycaemic control in diabetic patients, and to explore the possible link between glucose dysregulation and neurodegenerative dementia using 9 year follow-up data from the Kungsholmen project.

\section{Methods}

Study population The study population was derived from the Kungsholmen project, which is a population-based prospective study on ageing and dementia as fully described elsewhere [26, 27]. In brief, all registered inhabitants who were living in the Kungsholmen district of Stockholm, Sweden, and were aged $\geq 75$ years on 1 October 1987 were initially invited to participate in the project. At baseline (1987-1989), a two-phase survey consisting of a screening phase and a clinical phase was implemented. The screening phase included a health interview and administration of the Mini-Mental State Examination (MMSE) for 1,810 (76.4\%) participants. In the clinical phase, all participants who screened positive (MMSE $\leq 23$ ) and an age- and sex-stratified random sample of participants who screened negative (MMSE $>23$ ) were invited to undertake a comprehensive physical, neurological and psychiatric examination. During the clinical phase, 110 participants refused and 225 were diagnosed as having prevalent dementia according to the Diagnostic and Statistical Manual of Mental Disorders, revised third edition (DSM-III-R) criteria [28]. Thus, 1,475 participants were included in the dementia-free cohort. Of them, two had mental disorders and 172 refused to participate in the first follow-up examination (1991-1993) or had moved, and an additional 53 participants had missing baseline blood glucose data, leaving 1,248 participants for the current study.

During the first follow-up, 290 people died and 958 underwent clinical assessment. Of the 768 non-demented participants identified at first follow-up examination, 174 died during the second follow-up, 42 refused to participate and 552 were further assessed (1994-1996) leading to the identification of 445 still non-demented individuals. At the third follow-up examination (1997-1998), of these 445 participants, 103 had died, 311 received a dementia assessment and 31 dropped out due to refusal or moving (Fig. 1). Medical records and death certificates were available for all participants who died during the three follow-up periods.

Informed consent was received from all participants or from informants when the person was cognitively impaired. The Ethics Committee at the Karolinska Institutet approved all phases of the Kungsholmen project.

Baseline data collection Data on age, sex and education were collected from participants at baseline following standardised protocols [26, 27]. Education was measured by the maximum years of formal schooling, and was dichotomised ( $\geq 8$ vs $<8$ years) according to our previous study [29]. Global cognitive functioning was assessed with the MMSE. Weight and height were measured with a standard scale in light clothing and with no shoes. BMI was calculated as weight $(\mathrm{kg})$ divided by height $(\mathrm{m})$ squared. Arterial BP (i.e. systolic Korotkoff phase I and diastolic phase $\mathrm{V}$ ) was measured on the right arm by nurses with the participant in a sitting position after at least a $5 \mathrm{~min}$ rest. Information on medical history was taken for all participants from the inpatient register system, which encompassed all hospitals in Stockholm from 1969 onward [30]. The register system recorded up to six disorders that had been diagnosed during each hospitalisation. The International Classification of Disease, 8th Revision (ICD-8) had been used by the register system until 1986; since 1987 the ICD-9th Revision (ICD-9) has been employed (see www. wolfbane.com/icd/index.html, accessed 23 February 2009). Medical conditions derived from the inpatient register database included ischaemic heart disease (ICD-8, -9 codes 410-414), heart failure or left ventricular failure or other myocardial insufficiency (ICD-8 codes 427 and 428; ICD-9 


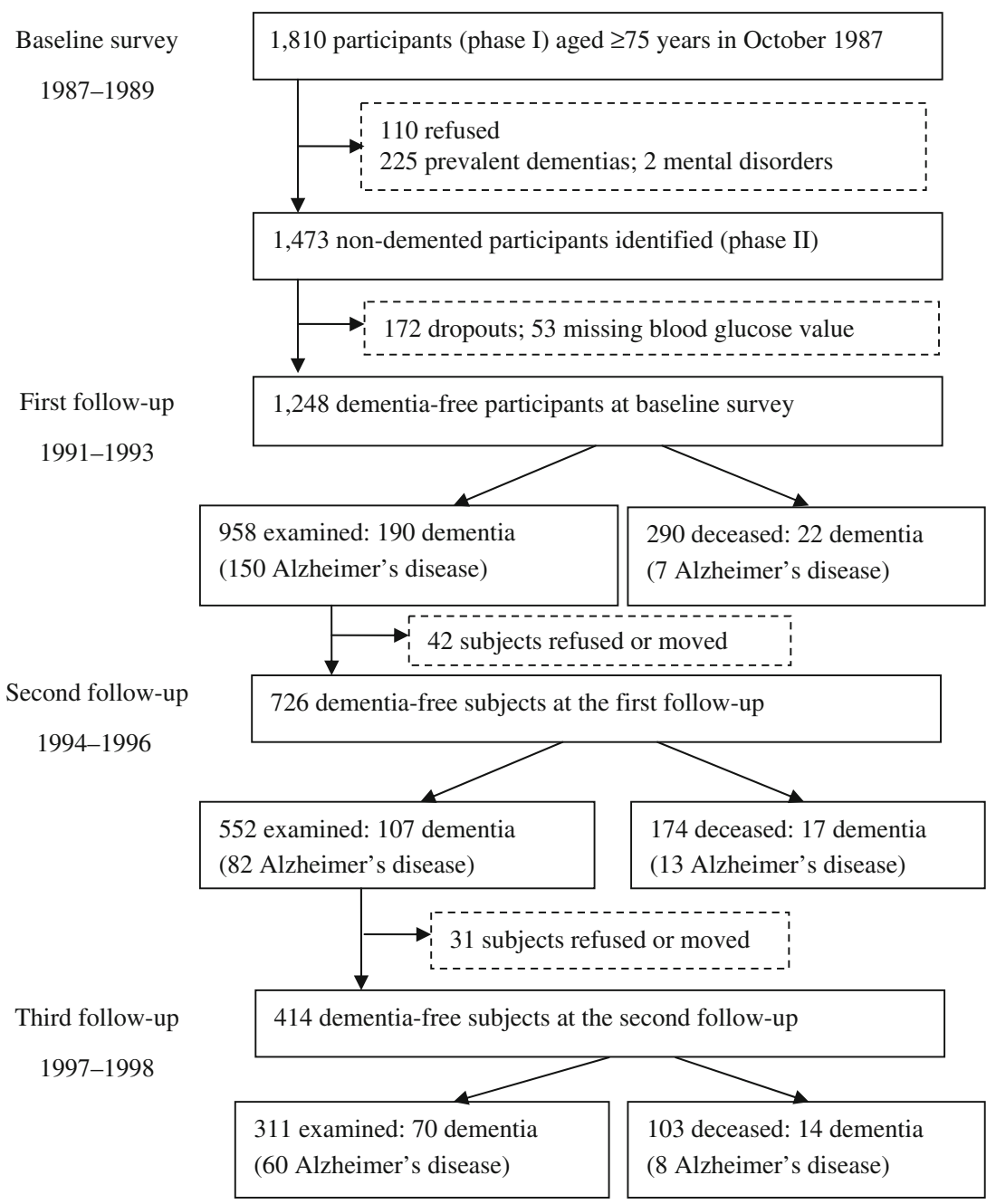

Fig. 1 Flowchart of the study population in the Kungsholmen Project

code 428.x), atria fibrillation (ICD-8 code 427.9; ICD-9 code 427), stroke (ICD-8, -9 codes 430-438), hypertension (ICD-8 codes 400-404; ICD-9 codes 401-405) and diabetes (ICD-8, -9 code 250). Information on medical drug use for the 2 weeks prior to the baseline interview was collected from the participants. Medical drugs were coded according to the Anatomical Therapeutic Chemical (ATC) classification system [31]. Hypoglycaemic drugs included hypoglycaemic medications or insulin injection (ATC code A10). Antihypertensive drugs were defined as all medicines potentially used for lowering BP (ATC codes $\mathrm{C} 02, \mathrm{C} 03$ and C07). Genomic DNA was prepared from peripheral blood samples that were taken at baseline, and apolipoprotein $\mathrm{E}$ gene $(A P O E)$ allelic status was determined following a standard procedure.

Definition of borderline diabetes and diabetes Blood samples were taken at both the screening and the clinical phase during the baseline survey, and each follow-up examination. Random blood glucose was measured using a glucose oxidase procedure at baseline and first follow-up examination, and $\mathrm{HbA}_{1 \mathrm{c}}$ assays (normal range 3.0-4.3\%) were carried out using a Mono S HPLC method (Pharmacia, Uppsala, Sweden) at the second and third follow-up examinations. Diabetes was identified as being recorded in the inpatient register system, or use of hypoglycaemic drugs, or a random blood glucose level $\geq 11.0 \mathrm{mmol} / 1$ at baseline (or $\mathrm{HbA}_{1 \mathrm{c}}$ level $\geq 6.4 \%$ at second and third followup examination) $[15,32]$. The last criterion included all cases of 'undiagnosed diabetes' when neither history of diabetes nor hypoglycaemic drugs use was present [33]. Overall diabetes was stratified as three subgroups according to random blood glucose levels of $<7.8,7.8-11.0$ and $\geq 11.0 \mathrm{mmol} / 1$ in data analyses. Borderline diabetes was considered to be present if random blood glucose levels were $7.8-11.0 \mathrm{mmol} / \mathrm{l}$ (or $\mathrm{HbA}_{1 \mathrm{c}}$ levels of $4.3-6.4 \%$ at second and third follow-up) in diabetes-free participants $[32,34]$.

Diagnosis of incident dementia, Alzheimer's disease and $\mathrm{VaD}$ At each follow-up, all participants underwent a 
comprehensive clinical examination and cognitive tests. Cognitive functions were tested by asking for facts of general knowledge and past personal information (semantic and episodic memory); by object naming and comprehension of commands and sentences (language); by problem solving and interpretation of proverbs (abstract thinking); by copying figures (visuospatial ability); and by calculation and solving mathematical problems (calculation). Dementia was diagnosed on the basis of clinical judgement following the DSM-III-R criteria, in which a validated three-step diagnostic procedure was used as previously reported [27]. In brief, two examining physicians independently made a preliminary diagnosis, and in the case of disagreement, a third opinion was sought to reach a concordant diagnosis. The cases fulfilling the DSM-III-R criteria were denominated 'clinically definite dementia', in contrast with a category of 'questionable dementia', which was used when there was evident memory impairment and dysfunction of a second cognitive ability was questionable. In this analysis, we treated both groups as dementia. The diagnosis of Alzheimer's disease required gradual onset, progressive deterioration and lack of any other specific causes of dementia. The diagnosis of $\mathrm{VaD}$ required abrupt onset, stepwise deterioration, or history of stroke or focal deficits. Hachinski's scale was also used to support the differential diagnosis between Alzheimer's disease and VaD [35]. Our diagnostic criteria for Alzheimer's disease and $\mathrm{VaD}$ were equivalent to probable Alzheimer's disease according to the National Institute of Neurological and Communicative Disorders and Stroke-Alzheimer's Disease and Related Disorders Association criteria [36], and to the National Institute of Neurological Disorders and Stroke-Association Internationale pour la Recherche et l'Enseignement en Neurosciences criteria [37]. For the deceased participants, the diagnosis of dementia and its subtypes was made by two physicians through reviewing the medical records and death certificates.

Further, the Alzheimer's disease diagnoses were subdivided in two groups of Alzheimer's disease cases with history of stroke (but not temporally related to dementia onset), and Alzheimer's disease cases in the absence of any current or past vascular diseases (hypertension, cerebrovascular disease, ischaemic heart diseases, heart failure and atrial fibrillation) and diagnosed diabetes. Details of the reclassification procedure have been reported elsewhere [38].

Statistical analysis The baseline characteristics of participants with borderline diabetes, patients with diabetes, and participants without either of the conditions were compared using $\chi^{2}$ tests for categorical variables and one-way ANOVA for continuous variables. The incidence rates were calculated as the number of events occurring during the entire follow-up period divided by person-years of follow- up. Cox proportional-hazards models were used to estimate the HRs and 95\% CIs of dementia, Alzheimer's disease and VaD. For non-demented participants, the follow-up time was calculated from the date of baseline interview to the date of the last follow-up examination or death. For the demented participants, the follow-up time was estimated as the full time during which the participants were free of dementia plus half of the follow-up time during which dementia developed. The proportional-hazards assumption was confirmed by graphs and tests based on Schoenfeld residuals. Age, sex, education, baseline MMSE score, BMI, $A P O E$ genotype and vascular disorders (i.e. heart disease, stroke, antihypertensive drug use and BP) were considered as potential confounders. As borderline diabetes and diabetes are related to an elevated mortality, we also adjusted for survival status at follow-up [34]. All dementia, VaD, Alzheimer's disease, Alzheimer's disease with stroke and Alzheimer's disease without major vascular comorbidities and death were used as separate outcomes in the Cox regression analyses. In secondary analyses we modelled diabetes as a time-dependent covariate. The statistical analyses were performed using Stata SE 10 for Windows (Stata-Corp, College Station, TX, USA).

\section{Results}

At baseline, $75(6.2 \%)$ and $47(4.0 \%)$ of the 1,248 dementia-free participants were identified as having diabetes and borderline diabetes, respectively. The prevalence of diabetes in this population was comparable with the prevalence in a elderly Swedish population in 1987 [39]. Demographic and baseline characteristics of participants with borderline diabetes or diabetes and participants without these conditions are compared in Table 1. Of the 75 patients with diabetes, $64(85.3 \%)$ were registered as having diabetes in the inpatient registry or reported use of hypoglycaemic drugs and $11(14.7 \%)$ were detected as having undiagnosed diabetes. Among the 64 participants with diagnosed diabetes, $42(65.6 \%)$ had blood glucose levels $\geq 11.0 \mathrm{mmol} / 1$. The modality of detection, treatment and blood glucose levels in participants with diabetes and borderline diabetes are reported in Table 2.

During a 9 year follow-up (6,328 person-years; mean per person $=5.1$ years; maximum $=10.5$ years) period, 420 participants were diagnosed with dementia, including 320 with Alzheimer's disease and 47 with VaD. Among the 320 Alzheimer's disease cases, 78 had previous, temporally unrelated stroke, and 137 had no major vascular comorbidities. Using either the standard or the time-dependent Cox models, we found that overall diabetes was associated with an increased risk of $\mathrm{VaD}$, and borderline diabetes was related to increased risk of dementia and Alzheimer's 
Table 1 Baseline characteristics of the study population $(n=1,248)$ by borderline diabetes and diabetes

\begin{tabular}{|c|c|c|c|c|}
\hline \multirow[t]{2}{*}{ Characteristics } & \multicolumn{3}{|l|}{ Participants } & \multirow[t]{2}{*}{$p$ value } \\
\hline & Normal $(n=1,126)$ & Borderline diabetes $(n=47)$ & Diabetes $(n=75)$ & \\
\hline Age (years) & $81.4(4.9)$ & $82.2(5.2)$ & $81.6(5.2)$ & 0.549 \\
\hline Women, $n(\%)$ & $844(75.0)$ & $37(78.7)$ & $51(68.0)$ & 0.329 \\
\hline Educational level $\geq 8$ years, $n(\%)$ & $471(41.8)$ & $19(40.4)$ & $22(29.3)$ & 0.103 \\
\hline $\operatorname{MMSE}^{\mathrm{a}}$ score & $26.7(2.7)$ & $25.9(2.3)$ & $26.1(2.8)$ & 0.024 \\
\hline Heart disease, $n(\%)$ & $171(15.2)$ & $6(12.8)$ & $31(41.3)$ & $<0.001$ \\
\hline Stroke, $n(\%)$ & $134(11.9)$ & $2(4.3)$ & $11(14.7)$ & 0.204 \\
\hline SBP (mmHg) & $155.5(21.2)$ & $152.0(18.6)$ & $160.7(25.9)$ & 0.065 \\
\hline DBP (mmHg) & $81.4(10.8)$ & $76.3(9.6)$ & $79.4(9.1)$ & 0.003 \\
\hline Antihypertensive drug use, $n(\%)$ & $488(43.3)$ & $20(42.6)$ & $47(62.7)$ & 0.005 \\
\hline Blood glucose (mmol/1) & $5.1(9.4)$ & $8.7(8.1)$ & $11.7(4.6)$ & $<0.001$ \\
\hline \multicolumn{5}{|l|}{ Any $A P O E \varepsilon 4$ allele, $n(\%)$} \\
\hline No & $615(54.6)$ & $26(55.3)$ & $45(60.0)$ & \\
\hline Yes & $257(22.8)$ & $6(12.8)$ & $10(13.3)$ & \\
\hline Missing & 254 (22.6) & 15 (31.9) & $20(26.7)$ & 0.123 \\
\hline \multicolumn{5}{|l|}{ BMI $\left(\mathrm{kg} / \mathrm{m}^{2}\right), n(\%)$} \\
\hline$<25$ & $664(59.0)$ & 29 (61.7) & $37(49.3)$ & \\
\hline $25-29.99$ & $272(24.2)$ & $11(23.4)$ & $23(28.0)$ & \\
\hline$\geq 30$ & $52(4.6)$ & $2(4.3)$ & $5(6.7)$ & \\
\hline Missing & $138(12.3)$ & $5(10.6)$ & $12(16)$ & 0.782 \\
\hline
\end{tabular}

Values are means (SD) unless indicated otherwise

${ }^{\text {a }}$ The MMSE score ranged from 0 (worst) to 30 (best)

DBP, diastolic BP; SBP, systolic BP

disease after controlling for possible confounders and vascular disease (Table 3). We further performed stratified analysis by subgrouping patients with diabetes according to levels of random blood glucose and diagnostic status. Compared with the reference group, patients with undiagnosed diabetes had a substantially increased risk of dementia, Alzheimer's disease and $\mathrm{VaD}$ after controlling for vascular disorders and other confounders. However, diabetic patients with random blood glucose levels $<7.8 \mathrm{mmol} / \mathrm{l}$ showed no increased risk of developing dementia, Alzheimer's disease and VaD.

Table 4 shows the basic-adjusted and the multi-adjusted HRs of Alzheimer's disease with stroke and Alzheimer's disease without major vascular comorbidities in relation to borderline diabetes and undiagnosed diabetes. Borderline and undiagnosed diabetes were further related to an increased incidence of Alzheimer's disease without vascular comorbidities.

During the 9 year follow-up, 71 (58.2\%) participants with either borderline diabetes or diabetes died. Cox regression analysis showed that borderline diabetes and diabetes were associated with elevated mortality (HR 1.50, 95\% CI 1.07-2.14). In the supplementary analyses, similar results were obtained when we used only the second follow-up data (i.e. the dementia-free cohort that was identified at the first follow-up examination, $n=726,124$ dementia cases, 94 Alzheimer's disease cases), and when we repeated the analyses among participants who survived
Table 2 Patients with diabetes $(n=75)$ by modality of treatment and random blood glucose levels $(\mathrm{mmol} / \mathrm{l})$

\begin{tabular}{lllll}
\hline Modality of treatment & No. of patients & \multicolumn{3}{l}{ Blood glucose levels (mmol/l), $n(\%)$} \\
\cline { 3 - 5 } & & $<7.8$ & $7.8-11.0$ & $\geq 11.0$ \\
\hline Oral hypoglycaemic drugs & 41 & $6(14.6)$ & $13(31.7)$ & $22(53.7)$ \\
Insulin with or without oral drugs & 4 & - & - & $4(100.0)$ \\
No treatment & 19 & $9(47.4)$ & $5(26.3)$ & $5(26.3)$ \\
Undiagnosed diabetes & 11 & - & - & $11(100.0)$ \\
\hline
\end{tabular}


Table 3 Risk of dementia, Alzheimer's disease and VaD related to borderline diabetes and diabetes by blood glucose levels

\begin{tabular}{|c|c|c|c|c|c|c|}
\hline \multirow[t]{2}{*}{ Exposure status } & \multicolumn{2}{|c|}{ All dementias $(n=420)$} & \multicolumn{2}{|c|}{ Alzheimer's disease $(n=320)$} & \multicolumn{2}{|l|}{$\operatorname{VaD}(n=47)$} \\
\hline & Model $1^{\mathrm{a}}$ & Model $2^{\mathrm{b}}$ & Model $1^{\mathrm{a}}$ & Model $2^{\mathrm{b}}$ & Model $1^{\mathrm{a}}$ & Model $2^{\mathrm{b}}$ \\
\hline Normal & 1.00 (Ref.) & 1.00 (Ref.) & 1.00 (Ref.) & 1.00 (Ref.) & 1.00 (Ref.) & 1.00 (Ref.) \\
\hline Borderline diabetes & $1.46(1.01-1.93)$ & $1.77(1.10-2.84)$ & $1.29(1.03-1.88)$ & $1.87(1.11-3.14)$ & - & - \\
\hline Time-dependent & $1.41(1.03-1.93)$ & $1.81(1.06-3.03)$ & $1.65(1.06-3.87)$ & $1.92(1.05-3.46)$ & - & - \\
\hline Diabetes & $1.37(0.92-2.06)$ & $1.37(0.88-2.12)$ & $1.04(0.61-1.79)$ & $1.19(0.68-2.12)$ & $2.64(1.12-6.26)$ & $3.21(1.20-8.63)$ \\
\hline$<7.8 \mathrm{mmol} / 1$ & $0.83(0.26-2.16)$ & $0.68(0.22-2.16)$ & $0.41(0.06-2.94)$ & $0.34(0.05-2.43)$ & - & - \\
\hline $\begin{array}{l}7.8-11.0 \mathrm{mmol} / 1 \\
\geq 11.0 \mathrm{mmol} / \mathrm{l}\end{array}$ & $1.18(0.51-2.71)$ & $0.87(0.54-2.66)$ & $1.26(0.45-3.52)$ & $1.26(0.46-3.62)$ & $1.50(0.35-23.50)$ & $2.88(0.35-23.50)$ \\
\hline Diagnosed & $1.52(0.68-2.85)$ & $1.43(0.70-2.94)$ & $1.06(0.53-2.15)$ & $1.08(0.40-2.95)$ & $3.03(1.03-9.83)$ & $3.61(1.02-12.89)$ \\
\hline Undiagnosed & $2.82(1.25-6.33)$ & $3.37(1.48-7.68)$ & $2.86(1.06-7.71)$ & $3.29(1.20-9.01)$ & $8.08(1.93-13.83)$ & $10.21(3.33-14.85)$ \\
\hline Time-dependent & $1.19(0.88-2.33)$ & $1.22(0.81-2.43)$ & $1.06(0.67-1.88)$ & $1.07(0.59-2.33)$ & $3.02(1.09-7.89)$ & $2.99(1.11-8.90)$ \\
\hline
\end{tabular}

Values are HR $(95 \% \mathrm{CI})$

${ }^{\text {a }}$ Adjusted for age, sex and education

Ref., reference

${ }^{\mathrm{b}}$ Adjusted for age, sex, education, baseline MMSE score, APOE genotype, follow-up survival status, BMI, heart disease, stroke, systolic BP, diastolic BP and antihypertensive drug use

until the time when dementia status was determined $(n=680,367$ dementia, 292 Alzheimer's disease and 36 VaD cases). Further, we performed the analyses by leaving out the 289 participants with missing values of $A P O E$ genotype or BMI, which produced results that were much the same as those from the initial analysis. Finally, exclusion of those with 'questionable dementia' from the analysis did not substantially alter the initial results (data not shown).

\section{Discussion}

In this long-term prospective study of a community-based cohort of elderly adults, we found that: (1) overall diabetes in general increased the risk of $\mathrm{VaD}$ only when glycaemic control was not taken into account in diabetic patients;
(2) uncontrolled diabetes was associated with an increased risk of both vascular and degenerative dementia; and (3) borderline diabetes was associated with Alzheimer's disease, and further with the subgroup of Alzheimer's disease without major vascular comorbidities. These findings suggest that the detrimental effect of diabetes on dementia might be alleviated by effective control of blood glucose, and that glucose dysregulation may be involved in neurodegenerative processes.

The main strengths of our study are the communitybased cohort, the long-term prospective study design, the comprehensive procedure for dementia diagnosis, the assessment of diabetes at baseline and each follow-up examination, the evaluation of the effect of diabetes on dementia risk taking into account glycaemic control in patients with diabetes, and the identification of Alzheimer's

Table 4 Risk of Alzheimer's disease with stroke, and Alzheimer's disease without hypertension, heart disease and stroke by borderline diabetes and undiagnosed diabetes

\begin{tabular}{|c|c|c|c|c|}
\hline \multirow[t]{2}{*}{ Exposure status } & \multicolumn{2}{|l|}{ With stroke $(n=78)$} & \multicolumn{2}{|c|}{ Without vascular comorbidities $(n=137)$} \\
\hline & Model $1^{\text {a }}$ & Model $2^{\mathrm{b}}$ & Model $1^{\mathrm{a}}$ & Model $2^{\mathrm{b}}$ \\
\hline Normal & 1.00 (Ref.) & 1.00 (Ref.) & 1.00 (Ref.) & 1.00 (Ref.) \\
\hline Borderline diabetes & $1.30(0.41-4.13)$ & $1.93(0.59-6.28)$ & $2.94(1.35-6.39)$ & $2.85(1.29-6.30)$ \\
\hline Undiagnosed diabetes & $3.67(0.51-26.71)$ & $3.75(0.48-4.55)$ & $2.92(1.09-13.41)$ & $4.74(1.08-18.46)$ \\
\hline
\end{tabular}

Values are HR $(95 \% \mathrm{CI})$

${ }^{a}$ Adjusted for age, sex and education

${ }^{\mathrm{b}}$ Adjusted for age, sex, education, baseline MMSE score, APOE genotype, follow-up survival status, BMI, systolic BP and diastolic BP Ref., reference 
disease without vascular disease. However, some limitations need to be pointed out. First, we used random blood glucose at baseline and first follow-up examination. As the receiver operating curve is $0.75(0.49-0.80)$ for detecting undiagnosed diabetes using random blood glucose [27], patients with impaired glucose tolerance might have been misclassified as non-diabetes and non-borderline diabetes groups, which would bias the results of our overall and subgroup analyses towards the null hypothesis. Second, the statistical power was limited for these stratified analyses due to the small number of diabetic patients in each subgroup. Even so, we found a significant association between undiagnosed diabetes and Alzheimer's disease. In this regard, the statistical power may not be a problem. Third, the Kungsholmen project is based on a communitybased cohort of very old ages (mean age was 82 years at baseline). The dropouts from screening phase to third follow-up examination were mainly due to death, refusal and moving from the area. In fact, after excluding those who died, the rate of participation at each phase varied between $85 \%$ and $94 \%$ [40]. However, both diabetes and dementia are associated with an elevated mortality, which would probably lead to an underestimation of the strength of the diabetes-dementia association due to selective survival. Therefore, caution is required when generalising our findings to younger populations. Fourth, we were unable to examine the role of insulin resistance in the association of diabetes with dementia due to absence of blood insulin measurements in our study. Finally, the diagnoses of Alzheimer's disease and $\mathrm{VaD}$ were made on a clinical basis. However, the clinical assessment for dementia was comprehensive and precise in our study, and the proportion of Alzheimer's disease without major vascular comorbidities in all Alzheimer's disease cases in our study is similar to the reports from a pathological study [41]. Even if neuroimaging is available, these data may help to detect vascular lesions in the brain, but cannot determine the significance of these lesions, as coexistence of Alzheimer's disease pathological change and vascular lesions in the brain is fairly common in the elderly [42].

Over the last decade, many population-based studies have reported a relationship between diabetes and dementia with some inconsistent findings. In fact, some longitudinal studies reported an association between diabetes and Alzheimer's disease $[4,7,11,25,43]$ or observed such an association only in specific subgroups [12, 13, 15], but others did not $[5,6,8]$. We found that well-controlled diabetes (diabetes with random blood glucose $<7.8 \mathrm{mmol} / \mathrm{l}$ ) was not significantly related to dementia risk. However, uncontrolled diabetes did not predispose to any type of dementia and was associated with increased risk of both Alzheimer's disease and VaD. Our findings may contribute to explain the controversial results among previous studies that addressed the association between diabetes and dementia without taking into account blood glucose control and diagnostic status in diabetic patients.

Diabetes is closely associated with vascular diseases, which may act as confounders or mediators in the association between diabetes and dementia. It is indeed likely that vascular disease can serve as both an independent risk factor and as a mediator in the association between diabetes and dementia. We previously reported that diabetes is associated with an increased risk of dementia and $\mathrm{VaD}$ [15], and borderline diabetes increased the risk of Alzheimer's disease, independently of vascular disease [34]. In the present study, to further examine the role of vascular comorbidities in the association between diabetes and Alzheimer's disease, a subgroup having Alzheimer's disease without major vascular comorbidities was identified after exclusion of Alzheimer's disease cases with comorbid vascular disorder. We found that borderline diabetes and undiagnosed diabetes were associated with an increased incidence of Alzheimer's disease without major vascular comorbidities, suggesting a direct link between glucose dysregulation and neurodegeneration. However, the relationship of diabetic patients with blood glucose levels of 7.8-11.0 mmol/l and dementia risk was not statistically significant and seemed to be less strong than the association of borderline diabetes with dementia. The possible explanations might be that: (1) the statistical power was limited to the stratified analyses due to the small number of diabetic patients in this subgroup $(n=18)$; (2) diabetic patients were aware of the disease situation and might have modified their lifestyle, but participants with borderline diabetes were not; and (3) insulin resistance in people with borderline diabetes might be stronger than in diabetic patients. Clinical and epidemiological studies have revealed that hyperinsulinaemia or insulin resistance is one of the suggested mechanisms to explain the increased risk of Alzheimer's disease in diabetic patients [44].

Neuroimaging studies have demonstrated the relationship of diabetes with cerebral atrophy, including cortical and subcortical atrophy, and to medial temporal lobe atrophy specifically [17]. Several possible mechanisms can explain the effect of glucose deregulation on neurodegeneration. First, hyperglycaemia has toxic effect as it can lead to slowly progressive functional and structural abnormalities in the brain [45]. Chronic hyperglycaemia could be one of the determinants of cognitive changes due to the accumulation of AGE, oxidative stress and cerebral microvascular and macrovascular atherosclerotic disease [46]. The glucose-mediated effects on cognition and brain structure might accelerate brain ageing. In addition, neurotoxic AGE caused by hyperglycaemia may contribute to the formation of neurofibrillary tangles and neuritic plaques [47]. Second, insulin resistance, especially in earlystage diabetes, is associated with compensatory hyperinsuli- 
naemia. Alteration in insulin could affect amyloid metabolism by changes of insulin in the brain and its receptor. Insulin appears to stimulate beta-amyloid peptide secretion and inhibit the extracellular degradation of beta-amyloid by competition for insulin-degrading enzyme (IDE) [48]. Insulin signalling defects may increase hyperphosphorylation of tau protein, which can lead to neurofibrillary tangles [47]. Third, inflammatory markers, including C-reactive protein, IL-6 and TNF- $\alpha 1$ are associated with diabetes and also contribute to the development of Alzheimer's disease [49]. Finally, several genetic studies have shown that chromosome 10 contains the genes for IDE and potentially the genes for both late-onset Alzheimer's disease and type 2 diabetes [44]. IDE has been demonstrated to degrade insulin and beta-amyloid, and to inhibit formation and cytotoxicity of islet amyloid polypeptide oligomer, a protein coexpressed and secreted with insulin by beta cells. There may be shared predisposition for developing islet amyloid in patients with diabetes and brain amyloid in those with Alzheimer's disease. A population-based clinicopathological study has shown the possible link between neurodegenerative processes that lead to loss of cortical brain cells in Alzheimer's disease and the loss of beta cells in type 2 diabetes [50].

In conclusion, our results show that uncontrolled diabetes is associated with increased risk of dementia including vascular and degenerative dementia. The detrimental effect of diabetes on dementia might be alleviated by effective control of blood glucose. The findings that borderline and undiagnosed diabetes are further related to Alzheimer's disease without vascular comorbidities suggest a direct link between glucose dysregulation and neurodegeneration. Further large, population-based cohort studies that include detailed assessment of cognition, preferably in combination with neuroimaging, and diabetes-related factors (such as diabetes duration, the effect of diabetes treatment on blood glucose level and the measurement of blood insulin) as well as comorbid conditions are required.

Acknowledgement Research grants were received from the American Alzheimer's Association (IIRG-03-5963), the Swedish Research Council in Medicine and the Swedish Brain Power. This study was also supported in part by funds from the Gamla Tjänarinnor, the Bertil Stohnes Foundation, Alzheimerfonden, Lindhes Advokatbyrå and Stiftelsen Solstickans (Sweden). We thank all staff of the Kungsholmen Project for their collaboration in data collection and management.

Duality of interest The authors declare that there is no duality of interest associated with this manuscript.

\section{References}

1. Cole AR, Astell A, Green C, Sutherland C (2007) Molecular connexions between dementia and diabetes. Neurosci Biobehav Rev 31:1046-1063
2. Alberti KG (2007) Screening and diagnosis of prediabetes: where are we headed? Diabetes Obes Metab 9(Suppl 1):12-16

3. Ferri CP, Prince M, Brayne C et al (2005) Global prevalence of dementia: a Delphi consensus study. Lancet 366:2112-2117

4. Ott A, Stolk RP, van Harskamp F, Pols HA, Hofman A, Breteler MM (1999) Diabetes mellitus and the risk of dementia: The Rotterdam Study. Neurology 53:1937-1942

5. Luchsinger JA, Tang MX, Stern Y, Shea S, Mayeux R (2001) Diabetes mellitus and risk of Alzheimer's disease and dementia with stroke in a multiethnic cohort. Am J Epidemiol 154:635-641

6. Hassing LB, Johansson B, Nilsson SE et al (2002) Diabetes mellitus is a risk factor for vascular dementia, but not for Alzheimer's disease: a population-based study of the oldest old. Int Psychogeriatr 14:239-248

7. Peila R, Rodriguez BL, Launer LJ (2002) Type 2 diabetes, APOE gene, and the risk for dementia and related pathologies: The Honolulu-Asia Aging Study. Diabetes 51:1256-1262

8. MacKnight C, Rockwood K, Awalt E, McDowell I (2002) Diabetes mellitus and the risk of dementia, Alzheimer's disease and vascular cognitive impairment in the Canadian Study of Health and Aging. Dement Geriatr Cogn Disord 14:77-83

9. Luchsinger JA, Tang MX, Shea S, Mayeux R (2004) Hyperinsulinemia and risk of Alzheimer disease. Neurology 63:11871192

10. Schnaider Beeri M, Goldbourt U, Silverman JM et al (2004) Diabetes mellitus in midlife and the risk of dementia three decades later. Neurology 63:1902-1907

11. Arvanitakis Z, Wilson RS, Bienias JL, Evans DA, Bennett DA (2004) Diabetes mellitus and risk of Alzheimer disease and decline in cognitive function. Arch Neurol 61:661-666

12. Borenstein AR, Wu Y, Mortimer JA et al (2005) Developmental and vascular risk factors for Alzheimer's disease. Neurobiol Aging 26:325-334

13. Akomolafe A, Beiser A, Meigs JB et al (2006) Diabetes mellitus and risk of developing Alzheimer disease: results from the Framingham Study. Arch Neurol 63:1551-1555

14. Irie F, Fitzpatrick AL, Lopez OL et al (2008) Enhanced risk for Alzheimer disease in persons with type 2 diabetes and APOE epsilon4: the Cardiovascular Health Study Cognition Study. Arch Neurol 65:89-93

15. Xu WL, Qiu CX, Wahlin A, Winblad B, Fratiglioni L (2004) Diabetes mellitus and risk of dementia in the Kungsholmen project: a 6-year follow-up study. Neurology 63:1181-1186

16. Hayden KM, Zandi PP, Lyketsos CG et al (2006) Vascular risk factors for incident Alzheimer disease and vascular dementia: the Cache County study. Alzheimer Dis Assoc Disord 20:93-100

17. van Harten B, de Leeuw FE, Weinstein HC, Scheltens P, Biessels GJ (2006) Brain imaging in patients with diabetes: a systematic review. Diabetes Care 29:2539-2548

18. Gao L, Matthews FE, Sargeant LA, Brayne C (2008) An investigation of the population impact of variation in $\mathrm{HbAlc}$ levels in older people in England and Wales: from a population based multi-centre longitudinal study. BMC Public Health 8:54

19. Shorr RI, de Rekeneire N, Resnick HE et al (2006) Glycemia and cognitive function in older adults using glucose-lowering drugs. J Nutr Health Aging 10:297-301

20. van den Berg E, Kessels RP, Kappelle LJ, de Haan EH, Biessels GJ (2006) Type 2 diabetes, cognitive function and dementia: vascular and metabolic determinants. Drugs Today (Barc) 42:741-754

21. Asimakopoulou KG, Hampson SE, Morrish NJ (2002) Neuropsychological functioning in older people with type 2 diabetes: the effect of controlling for confounding factors. Diabet Med 19:311-316

22. Yamada M, Kasagi F, Sasaki H, Masunari N, Mimori Y, Suzuki G (2003) Association between dementia and midlife risk factors: the Radiation Effects Research Foundation Adult Health Study. J Am Geriatr Soc 51:410-414 
23. Hassing LB, Hofer SM, Nilsson SE et al (2004) Comorbid type 2 diabetes mellitus and hypertension exacerbates cognitive decline: evidence from a longitudinal study. Age Ageing 33:355-361

24. Whitmer RA, Sidney S, Selby J, Johnston SC, Yaffe K (2005) Midlife cardiovascular risk factors and risk of dementia in late life. Neurology 64:277-281

25. Luchsinger JA, Reitz C, Honig LS, Tang MX, Shea S, Mayeux R (2005) Aggregation of vascular risk factors and risk of incident Alzheimer disease. Neurology 65:545-551

26. Fratiglioni L, Viitanen M, von Strauss E, Tontodonati V, Herlitz A, Winblad B (1997) Very old women at highest risk of dementia and Alzheimer's disease: incidence data from the Kungsholmen Project, Stockholm. Neurology 48:132-138

27. Fratiglioni L, Grut M, Forsell Y, Viitanen M, Winblad B (1992) Clinical diagnosis of Alzheimer's disease and other dementias in a population survey. Agreement and causes of disagreement in applying Diagnostic and Statistical Manual of Mental Disorders, Revised 3rd edn, Criteria. Arch Neurol 49:927-932

28. American Psychiatric Association (1987) Diagnostic and statistical manual of mental disorders, revised 3rd edn (DSM-III-R). American Psychiatric Association, Washington, DC

29. Qiu C, Backman L, Winblad B, Aguero-Torres H, Fratiglioni L (2001) The influence of education on clinically diagnosed dementia incidence and mortality data from the Kungsholmen Project. Arch Neurol 58:2034-2039

30. Qiu CX, Winblad B, Marengoni A, Klarin I, Fastbom J, Fratiglioni L (2006) Heart failure and risk of dementia and Alzheimer disease: a population-based cohort study. Arch Intern Med 166:1003-1008

31. Nordic Council on Medicines: Guidelines for ATC classification (1985). Nordic council on medicines (NLN Publication No. 16), Uppsala, Sweden

32. Nathan DM, Kuenen J, Borg R, Zheng H, Schoenfeld D, Heine RJ (2008) Translating the A1C assay into estimated average glucose values. Diabetes Care 31:1473-1478

33. Thomas MC, Walker MK, Emberson JR et al (2005) Prevalence of undiagnosed Type 2 diabetes and impaired fasting glucose in older British men and women. Diabet Med 22:789-793

34. Xu W, Qiu C, Winblad B, Fratiglioni L (2007) The effect of borderline diabetes on the risk of dementia and Alzheimer's disease. Diabetes 56:211-216

35. Hachinski VC, Iliff LD, Zilhka E et al (1975) Cerebral blood flow in dementia. Arch Neurol 32:632-637

36. McKhann G, Drachman D, Folstein M, Katzman R, Price D, Stadlan EM (1984) Clinical diagnosis of Alzheimer's disease: report of the NINCDS-ADRDA Work Group under the auspices of Department of Health and Human Services Task Force on Alzheimer's Disease. Neurology 34:939-944

37. Roman GC, Tatemichi TK, Erkinjuntti T et al (1993) Vascular dementia: diagnostic criteria for research studies. Report of the NINDS-AIREN International Workshop. Neurology 43:250-260

38. Aguero-Torres H, Kivipelto M, von Strauss E (2006) Rethinking the dementia diagnoses in a population-based study: what is Alzheimer's disease and what is vascular dementia? A study from the Kungsholmen Project. Dement Geriatr Cogn Disord 22:244-249

39. Andersson DK, Svardsudd K, Tibblin G (1991) Prevalence and incidence of diabetes in a Swedish community 1972-1987. Diabet Med 8:428-434

40. Xu W (2008) Diabetes mellitus and the risk of dementia: a population-based study. Karolinska Institutet. The outline of the thesis available from http://diss.kib.ki.se/2008/978-91-7357-516-4/, accessed 16 May 2008

41. Wilson RS, Scherr PA, Schneider JA, Tang Y, Bennett DA (2007) Relation of cognitive activity to risk of developing Alzheimer disease. Neurology 69:1911-1920

42. Lopez OL, Kuller LH, Becker JT et al (2005) Classification of vascular dementia in the Cardiovascular Health Study Cognition Study. Neurology 64:1539-1547

43. Leibson CL, Rocca WA, Hanson VA et al (1997) Risk of dementia among persons with diabetes mellitus: a population-based cohort study. Am J Epidemiol 145:301-308

44. Qiu WQ, Folstein MF (2006) Insulin, insulin-degrading enzyme and amyloid-beta peptide in Alzheimer's disease: review and hypothesis. Neurobiol Aging 27:190-198

45. Biessels GJ, Staekenborg S, Brunner E, Brayne C, Scheltens P (2006) Risk of dementia in diabetes mellitus: a systematic review. Lancet Neurol 5:64-74

46. Whitmer RA (2007) Type 2 diabetes and risk of cognitive impairment and dementia. Curr Neurol Neurosci Rep 7:373-380

47. Korf ES, White LR, Scheltens P, Launer LJ (2006) Brain aging in very old men with type 2 diabetes: the Honolulu-Asia aging study. Diabetes Care 29:2268-2274

48. Gasparini L, Xu H (2003) Potential roles of insulin and IGF-1 in Alzheimer's disease. Trends Neurosci 26:404-406

49. McGeer PL, Rogers J, McGeer EG (2006) Inflammation, antiinflammatory agents and Alzheimer disease: the last 12 years. J Alzheimers Dis 9:271-276

50. Janson J, Laedtke T, Parisi JE, O'Brien P, Petersen RC, Butler PC (2004) Increased risk of type 2 diabetes in Alzheimer disease. Diabetes 53:474-481 